colombiamedica.univalle.edu.co

Windows to History

\title{
Mucopolysaccharidosis type VI (Maroteaux-Lamy syndrome) in the pre-Columbian culture of Colombia
}

\section{Mucopolisacaridosis tipo VI (síndrome Maroteaux-Lamy) en la cultura precolombina de Colombia}

\author{
Harry Pachajoa ${ }^{\star 1}$, Carlos Armando Rodriguez ${ }^{2}$ \\ ${ }^{1}$ Centro de Investigaciones en Anomalías Congénitas y Enfermedades Raras. Universidad Icesi, Cali, Colombia \\ ${ }^{2}$ Facultad de Salud, Universidad del Valle, Cali, Colombia
}

Pachajoa H, Rodriguez CA. Mucopolysaccharidosis type VI (Maroteaux-Lamy syndrome) in the pre-Columbian culture of Colombia. Colomb Med. $2014 ; 45(2): 85-88$.

(c) 2014 Universidad del Valle. This is an Open Access article distributed under the terms of the Creative Commons Attribution License, which permits unrestricted use, distribution, and reproduction in any medium, provided the original author and source are credited.

\begin{abstract}
Article history:
Received: 21 October 2013

Revised: 28 May 2014

Accepted: 28 May 2014

Keywords:

Mucopolysaccharidosis VI, mucopolysaccharidoses, history of medicine, paleopathology, inborn genetic diseases.

Palabras clave:

Mucopolisacaridosis VI, mucopolisacaridosis, historia de la medicina, paleopatología, enfermedades genéticas congénitas
\end{abstract}

\begin{abstract}
Mucopolysaccharidosis type VI or Maroteaux Lamy syndrome is an autosomal recessive lysosomal storage disorder resulting from a deficiency of arylsulfatase B, the clinical features include short stature, hepatosplenomegaly, dysostosis multiplex, stiff joints, corneal clouding, cardiac abnormalities, and facial dysmorphism, with intelligence usually normal. We present evidence of the possible existence of Maroteaux Lamy syndrome in pre-Columbian pottery 2000 years ago, in the ColomboEcuadorian Pacific coast of the Tumaco-Tolita culture.
\end{abstract}

\begin{abstract}
Resumen
La mucopolisacaridosis tipo VI o síndrome de Maroteaux Lamy es una enfermedad de depósito lisosomal autosómica recesiva que resulta de una deficiencia de la enzima arilsulfatasa B, las características clínicas incluyen talla baja, hepatoesplenomegalia, disostosis múltiple, rigidez en las articulaciones, opacidad corneal, anomalías cardíacas, y dismorfismo facial, con inteligencia generalmente normal. Presentamos evidencia de la posible existencia de síndrome de Maroteaux Lamy en la cerámica precolombina desde hace 2000 años, en la costa pacífica Colombo-ecuatoriana pertenecientes a la cultura Tumaco-Tolita.
\end{abstract}

\footnotetext{
${ }^{*}$ Corresponding author:

Harry Pachajoa, Centro de Investigaciones en Anomalías Congénitas y

Enfermedades Raras. Universidad Icesi, Cali, Colombia

Email:hmpachajoa@icesi.edu.co
} 
Mucopolysaccharidosis type VI or Maroteaux Lamy syndrome is an autosomal recessive lysosomal storage disorder resulting from a deficiency of arylsulfatase B. Maroteaux et al., first described this disorder as a novel dysostosis associated with increased urinary excretion of chondroitin sulfate in $1963^{1}$.

Clinical features and severity are variable, but usually include short stature, hepatosplenomegaly, dysostosis multiplex, stiff joints, corneal clouding, cardiac abnormalities, and facial dysmorphism, with intelligence usually normal ${ }^{2}$.

We present a collection of pottery from the Tumaco-Tolita culture close to 2,000 years old with a possible representation of Maroteaux Lamy syndrome, which were evaluated by an archaeologist and a medical geneticist succeeded in identifying about 20 ceramic artifacts with representations of individuals with mucopolysaccharidosis type VI in about 10 museums and private collections in Ecuador and Colombia. The ceramic artifacts present phenotypical features like skeletal dysplasia, macrocephaly, mildly coarse facial features, broad mouth, prominent sternum, kyphosis, scoliosis (Fig. 1) probably constituting evidence of this disease in the pre-Hispanic Latin-American and past world. The differential diagnosis includes Hurler syndrome and various types of skeletal dysplasia.

The Tumaco-Tolita culture inhabited the region of the Pacific Colombo-Ecuadorian coast during the years $300 \mathrm{BCE}$ to 600

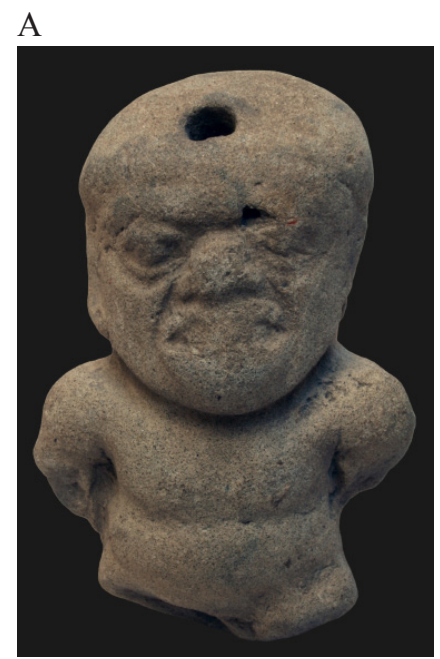

B

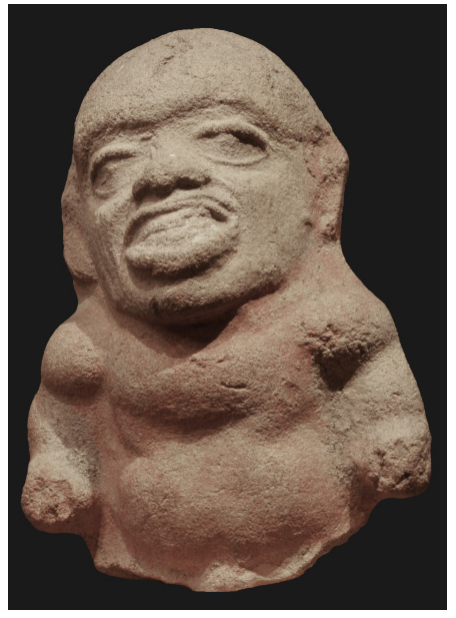

C

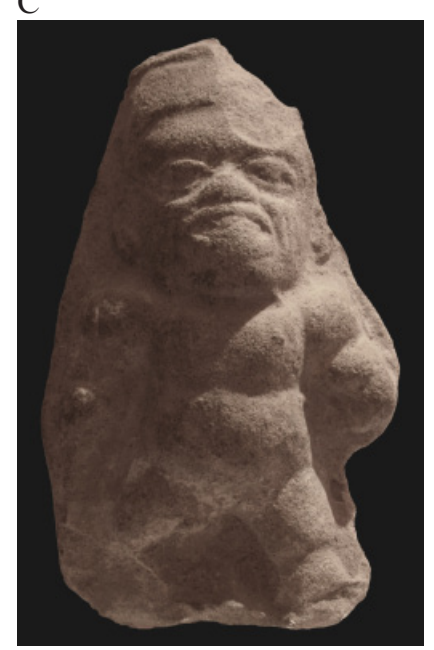

Figure 1. A, B and C. Pottery sample from the Tumaco-Tolita culture representing a possible case of Maroteaux Lamy syndrome.
CE. This culture was characterized for realistically representing the different pathologies affecting their population. In their pottery work, they show evidence of genetic illnesses like Down syndrome, achondroplasia, sirenomelia, and other congenital malformations $\mathrm{s}^{3-5}$. The representation of this syndrome in these populations could confirm the existence of this syndrome in these populations and, because of the high representation (20 ceramic pieces), it is suggested that it might have an increased prevalence, although it has not been possible to determine the population of these communities, and it is not possible to establish how many people had this disease, but the prevalence was almost certainly higher than currently reported for this syndrome ( 1 in 320,000 live newborns) $)^{6}$.

It is noteworthy that the figures represented are of young people or infants, clearly suggesting that the complications experienced by people with mucopolysaccharidosis type VI as cervical cord compression may have regulated the mortality of people with this disease, because at that time no orthopedic spine surgery was known to be practiced.

These types of pre-Hispanic indigenous communities, and especially the Tumaco-Tolita, lived in isolation, probably engaging in consanguineous marriages, as done by current indigenous Colombian communities, increasing the occurrence of recessive diseases and the possible existence of a founder effect.

Currently, the presence of this syndrome has been documented in indigenous communities in $\mathrm{Cauca}^{7}$ and the presence of one or two founder effects have been suggested in this area in the Colombian southwest ${ }^{8}$. Because of the lack of genetic population studies in pre-Hispanic osseous remains of the Tumaco-Tolita, it is not possible to ensure that this population was related to the current residents of Cauca.

\section{Conflict of interest:}

The authors declare that there is no conflict of interest that could be perceived as prejudicing the impartiality of the information reported.

\section{References}

1. Maroteaux P, Leveque B, Marie J, Lamy M. Une nouvelle dysostose avec elimination urinaire de chondroitine-sulfate $\mathrm{B}$. Presse Med. 1963; 71: 1849-52.

2. Azevedo AC, Schwartz IV, Kalakun L, Brustolin S, Burin MG, Beheregaray AP, et al. Clinical and biochemical study of 28 patients with mucopolysaccharidosis type VI. Clin Genet. 2004; 66(3): 208-13.

3. Pachajoa H, Rodriguez C. Possible case of sirenomelia in the Tumaco-Tolita pottery pre-Columbian culture, 2000 years before the epidemic focus of sirenomelia in Cali-Colombia. Am J Med Genet A. 2011; 155A: 2327-8.

4. Pachajoa H, Rodríguez CA. Down's Syndrome in pre-Hispanic pottery of the Colombia- Ecuador Pacific coast (2000 years ago) Neurologia. 2013; 28(1): 62. 
5. Rodríguez CA, Isaza C, Pachajoa H. Achondroplasia among ancient populations of mesoamerica and South America: Iconographic and Archaeological Evidence. Colomb Med (Cali). 2012; 43(3): 212-5.

6. Nelson J, Crowhurst J, Carey B, Greed L. Incidence of the mucopolysaccharidoses in western Australia. Am J Med Genet. 2003; 123A: 310-3.
7. Rosselli D, Rueda J-D, Solano M. Ethical and economic considerations of rare diseases in ethnic minorities: the case of mucopolysaccharidosis VI in Colombia. J Med Ethics. 2012; 38(11): 699-700.

8. Pachajoa H, Ariza Y, Villota V, Miño ME, Acosta-Aragón MA. Distribución geográfica de la mucopolisacridosis tipo VI en el centro del departamento del Cauca ¿es posible un efecto fundador?. Medellín: Editorial; 2013. 